\title{
Micro hydro power plant Shanping (Site reconstruction)
}

\author{
Štefan Tkáč \\ Technical University of Košice, \\ Faculty of Civil Engineering, \\ Department of Architectural Engineering \\ stefan.tkac@tuke.sk
}

\begin{abstract}
This research paper is part of the wider project concerning the very first detailed mapping of the overall Taiwanese hydro-power plants that took place from 2013 up to 2015 and it is currently in evaluation and finalization stage. The case of Shanping hydro-power plant has been carefully studied, photographed, documented and mapped in situ. It was one of the isolated hydro-power plant projects originally built to supply the remote area with the specific designation. Shanping hydro-power plant, as well as the other units from the early hydro-power generation era in Taiwan, are considered to be the technological heritage of civil and mechanical engineering that reflects later in all the further projects up to nowadays modern Taiwanese hydro-power plants. Unfortunately, most of the hydro-power houses from the older periods were severely damaged or destroyed by natural causes which were also the case of Shanping unit. The research is trying to reconstruct the original location of the powerhouse and its supporting structures based on available historical documents, previous studies, comparative methodology and the current on-site observation.
\end{abstract}

\section{Key words}

hydro-power, hydro-power plant, micro-energy, renewable energy, water energy

\section{Introduction}

The reconstruction of the Shanping hydro-power plant is an important part of the overall Taiwanese hydro-power plants mapping. Since the complex mapping research started in 2013, there have been multiple abandoned or long forgotten cases rediscovered lately, clearly pointing out that Taiwan had an extensive and vibrant private micro hydro-power development sector going far beyond the commonly well documented large powerhouses owned by the government. The search and evaluation of the historical materials are thus crucial exactly in this particular era since the entire Taiwanese power history is dated from 1903 and most of the people remembering the places, civil works, and historical circumstances are still alive. These micro hydro-power plants were also mostly the first efforts to power up the remote areas, hence struggle with typhoons, earthquakes, and landslides were significant, but well recorded which could be only essential for nowadays hydraulic civil works. Shanping powerhouse was also one of the predecessors of the further electrification of Taiwan, therefore it represents uniqueness in construction, turbine application and thus its worth to study. 


\section{Methodology}

The methodology was focused on solving three key tasks, namely:

1. Finding a suitable case studies that could serve as a model examples to answer possible civil and mechanical engineering questions that might arise along the study. For this task, a standard comparative method was chosen where mostly the Shanping powerhouse and its hydraulic structures were compared to several other historical hydro powerhouses in Taiwan that were already studied or are currently under review.

2. Creating a hypothetical drafting based on imagery and texts available online, using map to indicate the location of the individual hydraulic structures and verify the hypothesis by on-site mapping.

3. Drafting a digital reconstruction of the entire site based on all available materials.

\section{Comparison}

The roots of hydropower generation reach the years 1903-1905 when the Guishan hydropower plant was built and started its production becoming the very first hydropower plant in Taiwan. Later within the entire Taiwan area, hydropower plants were until the year 1962 leading source of electrical energy. Despite the mentioned fact that most of the old hydropower plants were struck by natural disasters, allied bombing during WWII or simply abandoned, it is something about 113 years of overall Taiwan's hydropower history, therefore, people directly working on Taiwanese hydropower plant projects, or their family members are in many cases still alive, so as the picture documentation since the majority of the projects were considered strategic military objects hence possibility to acquire quiet precise information and stories behind some of the truly unique designs.
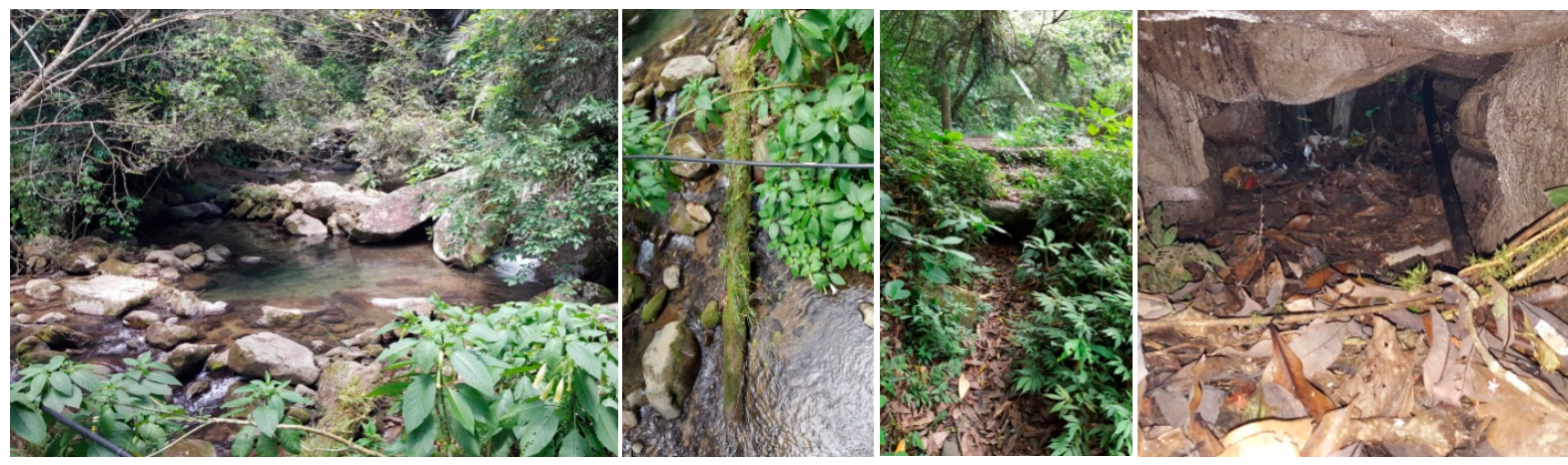

Fig. 1. clearly traceable remains of the Neiwan power house water structures on Matai old road (diversion weir, diversion channel and inflow). Pictures were taken during three mappings carried on August 25th, 2017, May 18th and 30th, 2018. (Source - Author)

It is said that civil engineering works are never the same, even if built at the same place, the hydropower plants are very specific as they are static as well as dynamic structures merging civil and mechanical engineering in one, many times in harmonic relationship with nature. Therefore the constructions are specifically bond with the needs of the environment and even after the severe damage; the traces left behind are still at the place in the form of corridors, pieces of civil works or water and sand engravings on the rocks[1]. 
Shanping hydropower plant was remote and considered a micro scale, which fells to the category of hydro energy structures that were in Taiwan called powerhouses rather than power plants. This matter could be traced back to the Japanese occupation era where most of the hydropower plants were, in fact, stand-alone structures rather than part of a wider network, which was implemented later. Based on the previous comments, civil structures vary in shapes, but the principle stays the similar, if not the same. Shanping hydropower plant had a diversion weir that was originally built with respect to the natural composition of rocks and to deliver the water from the weir to the powerhouse it uses an artificial $U$ shape waterway made by concrete. This structure could be seen in three other remote cases.

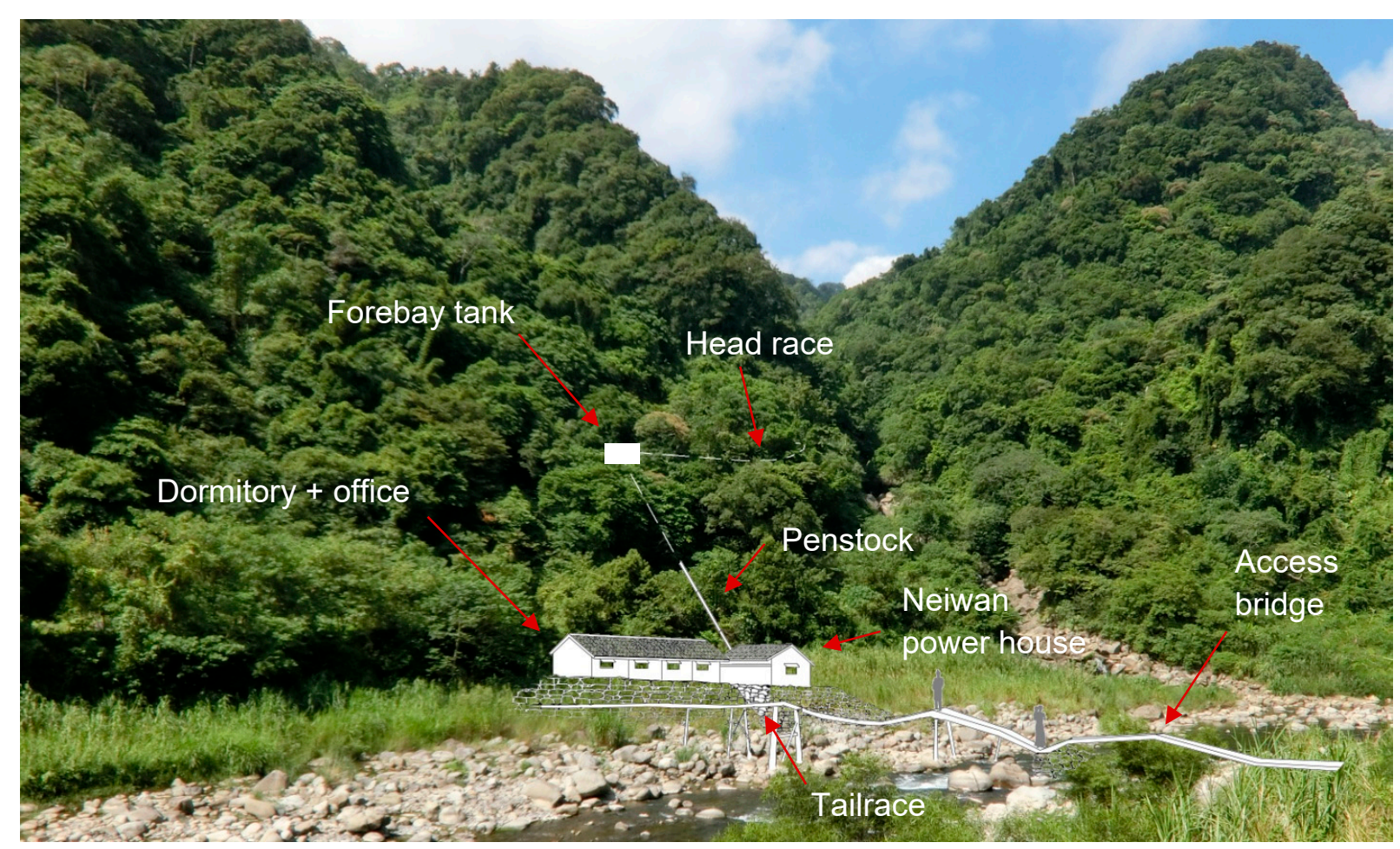

Fig. 2. Analysis and reconstruction of the Neiwan power plant site (Source - Author)

The first one is Neiwan power house from 1910 located little above the Neiwan Township on Mkmauty also known as Matai old road. Based on the remains it is assumed that Neiwan powerhouse had a very simple diversion weir consisted of naturally formed pond backed up by heavy stones with concrete spillway diverting water to supply channel made from a combination of natural stones and concrete, ending up by forebay tank and tubular penstock (Fig. 1,2),[2]. Another good example would be Ruanqiao hydro powerhouse built in 1919 as a support for Neiwan powerhouse. Although Ruanqiao was destroyed and abandoned after 1945 it was renewed between 1988-1992. It has a $7.7 \mathrm{~m}$ active head which is similar to Shanping and it is using diversion weir and long irrigation channel as a supply channel[3]. The last example would be Fanshekeng powerhouse from around 1908 which probably had the larger diversion weir then Neiwan, but smaller then Runchiao. It was made from natural stone segments with a concrete finish (pieces of the base could be still seen in the river bed) and a combination of natural stone 
and wood supply channel rose on to a bamboo construction ending with rectangular shape penstock made from steel[4].

\section{Study of historical imagery}

Historical maps, as well as satellite and orthophoto maps, were studied via GIS mapping systems Taiwan century historical map created by Academia Sinica and National Land Surveying and Mapping Center, Ministry of the Interior (NLSC). The historical imagery was retrieved from workers of Taipower Gāo píng hydropower plant/高屏發電廠 and various visitors of the Shanping area.

Study of historical documents included Photo Gallery of the Liouguei Forestry namely the photographs of Mr. Lin Jin-Rong who was one of the workers physically building the Shanping hydropower plant. Further documents from which the main information regarding the lifetime of the Shanping power plant was retrieved are The beauty of Shanping Forest Ecological Garden - The artists' acute observations and Shanping Forest Ecology Science Park Explanation Manual.

Several introduction video footages made by Council Agriculture Executive Yuan were also investigated, especially the Forest cinema's introduction of Nature within the Shanping education area where there are shots of the interior of the Shanping hydropower plant during operation as well as a view of the tailrace cascade.

\section{On-site mapping}

On-site measurement of the remaining structures was carried away on March 28th, 2017 and June 6th, 2018 which brought several development sketches (Fig. 15) of the probable original form of the hydropower civil structures. Physical observation included the Shanping working station, Shanping creek, former power plant site, waterway, green bridge site, Lover's bridge site and water monitoring station. The measurements were focused on dimensions of the waterway, remaining inflow structure and generator.

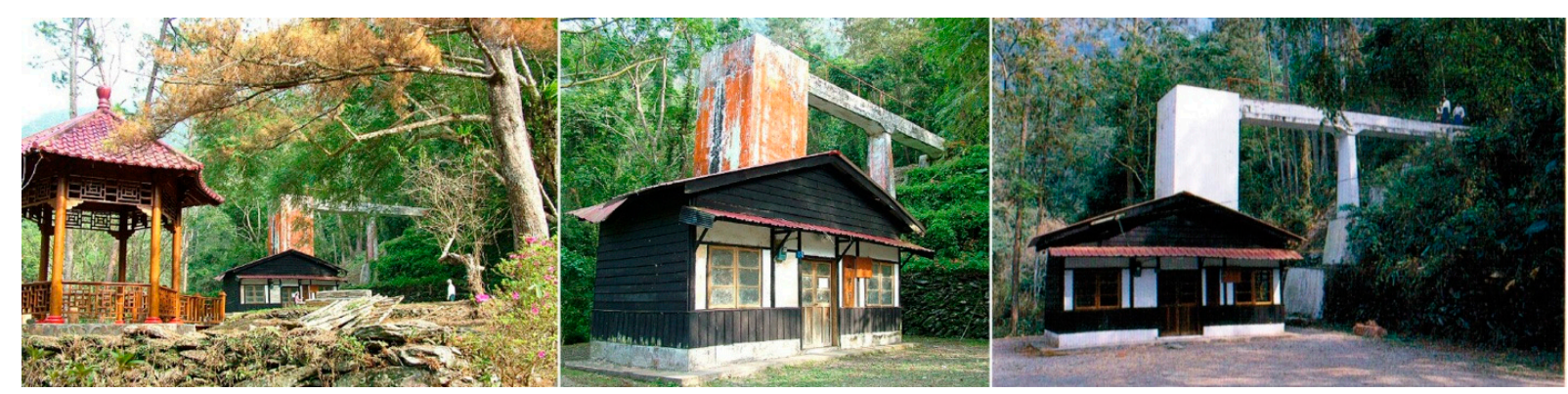

Fig. 3. Series of pictures of the Shanping hydropower plant before being struck by the typhoon Morakot on August 8th, 2009. (Source - Courtesy of the Council of Agriculture Executive Yuan[6].)

\section{Location}

Shanping hydropower plant study site is located in southern Taiwan, Kaoshiung City, Maolin District within the Shanping Forest Ecological Scientific Garden along the upper riverbed of the Shanping creek. 
To get to Shanping Forest Ecological Scientific Garden one needs to take the provincial highway no. 27 which goes through Maolin District. Before entering a bridge no. 5 in Zhongxing village turn right to Shanping lin road that leads straight to the Kaohsiung City Government Police Bureau, Liugui Branch Senshan Police Station which serve as Shanping checkpoint station for visitors entering the mountain area. Prior to entrance, every visitor needs to fill out the Shanping Forest Ecological Science Park Project Application Form. Shanping lin road then continues along the valley above the San he creek, which it later crosses via Shanping bridge no. 2 and continues towards Shanping bridge no.1 which crosses the Shanping creek and leads to the entrance of the Shanping Forest Ecological Scientific Garden.

\section{History of Shanping area}

The history of the area could be traced back to the aboriginal tribes, Dutch colonial period, Ming and Qing dynasty, but the real development starts during the Japanese occupation period when an extended campus of the Kyoto Imperial University was set up in Shanping with focus mainly on harvesting the quinine (Cinchona ledgeriana), but also forestry experiments and wood resources. After the liberation of Taiwan in 1945, the Shanping area expanded the original ongoing quinine research and established production and testing plant which last until 1970 when the synthesis of artificial quinine became available. The area then went through several administrative changes, but eventually became a research facility with the focus on forestry research and promotion of ecological conservation[5]. Shanping Forest Ecological Scientific Garden is today the most important forest research base in southern Taiwan. The area also serves as an education facility and a botanical garden dedicated to cultivating and nurturing a wide range of seeds and plant species. There is Shanping Nursery Garden, fields for Cinchona, Arboretums, and display of famous evergreen tree Phoebe nanmu. It is also a place for a variety of animals like Formosan black bear, frogs, crabs, fishes, 139 species of butterflies, various insects and two-thirds of Taiwan's bird species(134 bird species) hence the area nickname "birdwatching paradise". The historical value of the area is constantly reminded by the remaining Japanese wooden traditional architecture[7].

\section{Role of the Shanping hydro power house}

Shanping hydropower plant(Fig. 3.) known also as Shanping hydro powerhouse or room falls according to the installed capacity into the category of pico and after retrofitting into the micro hydropower plants[9]. It was designed by Taiwan Power Company, Gaoping power plant Liugui unit formerly known as Tulong power plant.

The main purpose was to supply Shanping area with more clean and sustainable power as an alternative to candles, batteries, kerosene lamps and diesel generators that were originally used to light and power the area. Power plant designs were carried away in 1951. The building process started in the year 1954 and ended at the end of the year 1956. Shanping powerhouse started generating electric power in February 1956. The power plant was equipped with horizontal axis Francis turbine powering generator via a belt, firstly generating $2,5 \mathrm{kWh}$ which was initially insufficiently low, therefore after redesigning and coordination process which resulted in higher installed capacity from 3 up to $5 \mathrm{~kW}$, it significantly increased the production up to $4,5 \mathrm{kWh}$. Even thou due to limitation caused by the volatility of the Shanping creek, on the one hand, the generated power was sufficient for night operation of the Shanping area, e.g. during rainy seasons with abundant water, the power supply time could reach late nights, up to 22:00. However, during winter and dry seasons the power supply range drops and supply could 
reach 20:00 only. It was mainly due to the fact that the power plant was designed in diversion and run of river scheme. Despite the naturally formed upstream retention ponds and the help of concrete diversion weir, the plant had very little or no accumulation capacities mainly due to environmental impact, therefore, the production was strongly dependent on actual flow volume which was the most significant during dry seasons when generation time was reported to be 4-5 hours only[5,7,10]. Although the Shanping hydropower plant was built in the 50 s to power a remote area with output $4,5 \mathrm{kWh}$ it also means that in 4 hours the generated power was $18 \mathrm{~kW}$ per day during the dry season and about $36 \mathrm{~kW}$ in 8 hours per day during the wet season. Thus the overall monthly output could range from min. $540 \mathrm{~kW}$ up to $1080 \mathrm{~kW}$ which is within the standard range of micro hydropower plant output in those days.

\section{The end of the Shanping hydropower house}

As the workers in the Shanping area felt unsecured due to electricity shortage and volatility, in 1972 the electric power transmission lines were installed in the area and Taipower started officially supply Shanping area. The Shanping hydro powerhouse was turned into a fully operable museum.

As a museum, Shanping hydropower house was intended to be renovated and promoted to the monument of technological value, but on August 8th, 2009 the severe typhoon Morakot[11]. caused several landslides in the area which generated sudden flash flood waves that led to Shanping creek riverbed width enlargement from the original 5 to $180 \mathrm{~m}$ (Fig. 4). Because Shanping hydro powerhouse was in the vicinity of the creek, it was struck by flood and flushed away along with diversion weir with green bridge, water supply channel along the old plank path, forebay, unique concrete shaft, tailrace cascade(Fig. 4). and several other structures that were part of the ecological park, namely temple of the Earth god, Lover's bridge, Pharmaceutical plant garden, hydrological station, camphor and charcoal huts, ecological pond for soil and rainwater retention and valuable arboretums along the creek valley.

\section{Remains of the Shanping hydropower house}

Despite the fact that the landscape has changed dramatically and was restored by TFRI Taiwan Forestry Research Institute, the remains that are still reminding presence of the former power plant structures could be found in the Shanping creek riverbed. There are both sides of the diversion weir with a piece of stairs that once lead to the green bridge, old plank forest path with diversion channel, concrete shaft and power plant's generator.

\section{The diversion weir}

During the typhoon, the whole weir was torn into parts and significantly shifted forward by a sudden flood from torrential rains and mostly replacement of the heavy stones falling from the naturally created dam above (Fig. 5). The weir was designed as a standard rectangular diversion weir with single-leaf water control gate placed on the top of the $140 \mathrm{~cm}$ high crest of the ogee type spillway. Most parts of the spillway including deflector are missing and were peeled off by cavitations during enormous water discharge which the spillway was obviously not designed to withstand. The main weir body construction consisted of reinforced concrete with 15 up to $30 \mathrm{~cm}$ wide wings. The water level was regulated by $600 \mathrm{~cm}$ wide and $120 \mathrm{~cm}$ high slide gate. The rails for the slide gate could be still visible in the concrete on both sides of the weir. By investigating old pictures and onsite remains of the weir, the access stairs were on the right side along with desilting opening as well as placement of the intake for the supply channel, the regulation wheels for the gate and supply channel was located on right(Fig. 7). Normally water 
flowed through intake to the supply channel, but after studying several old pictures it is visible that as the powerhouse was decommissioned in 1972 the sliding gates were removed, the reservoir in front of the weir became full of silt, therefore, the original intake opening was partially blocked and water was diverted via PE pipeline.
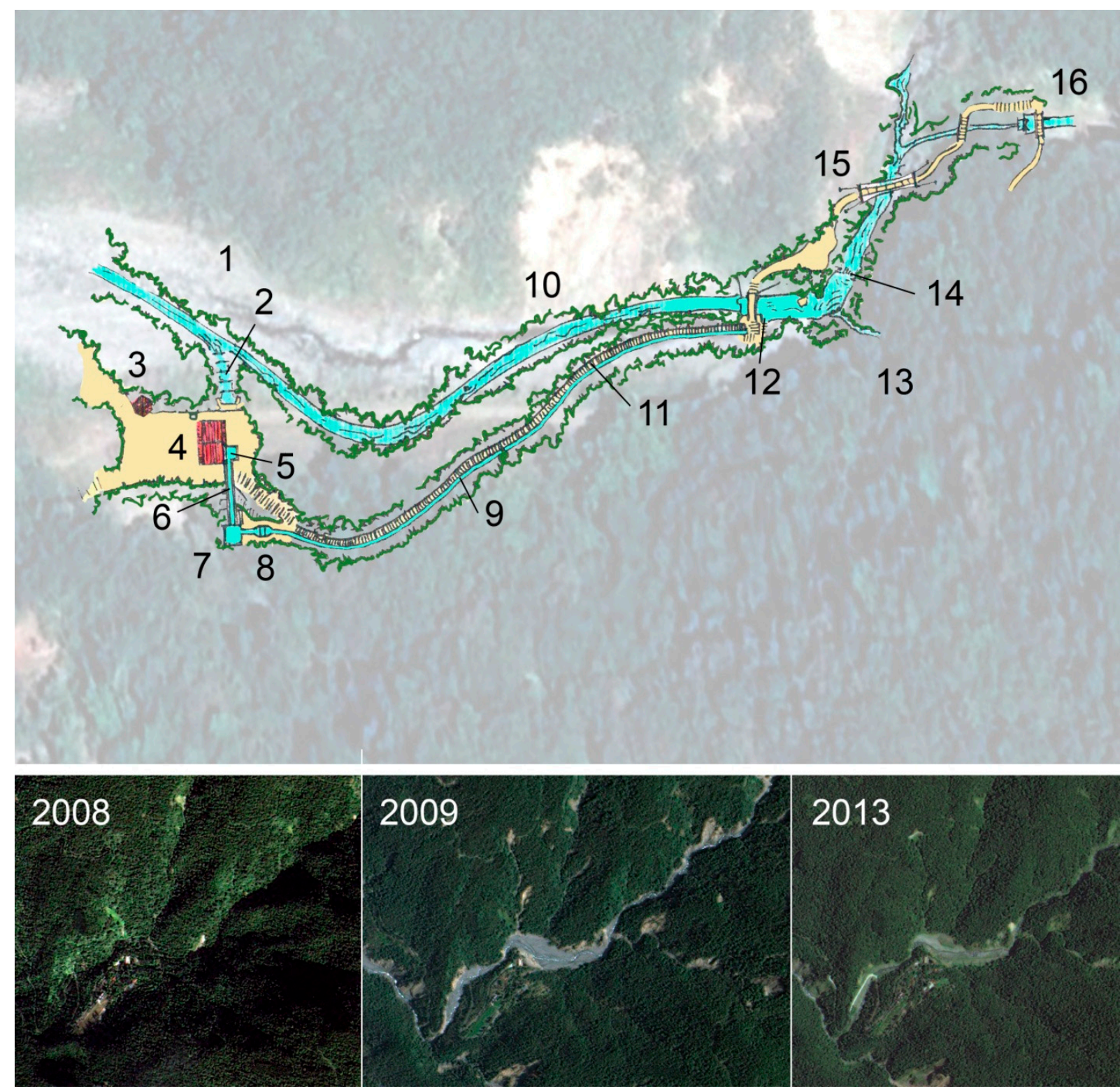

Fig. 4. (above)The original riverbed area in Shanping Forest Ecological Scientific Garden. 1 Tailrace, 2 - Tailrace cascade, 3 - Wooden shelter, 4 - Powerhouse, 5 - Shaft, 6 - Aqueduct, 7 Forebay, 8 - trash rack, 9 - Water channel, 10 - Shanping creek river bed, 11 - Old plank path, 12 - Intake weir \& green bridge, 13 - Waterfall, 14 - Small artificial weir for accumulation purposes, 15 - Lover's suspension bridge, 16 - Water metering station. (below) Satellite imagery showing changes of the Shanping creek riverbed before Typhoon Morakot in 2008, year after the disaster in 2009 and the newly restored area in 2013. (Source Author, Maps retrieved from the Center for GIS, RCHSS, Academia Sinica[8]) 
The inflow opening had a rectangular shape $35 \times 35 \mathrm{~cm}$ placed on the right side of the weir (Fig. 8). Currently, it is hidden behind a large rock which was probably moved there via strong water current. The desilting opening DN150 is placed at the bottom of the weir on the right covered by Blind Pipe Flange with $20 \mathrm{~cm}$ diameter mounted originally by 4 bolts but only 3 are remaining now. The desilting opening is covered by rust and moss and it is clear that it was not used for a long time.
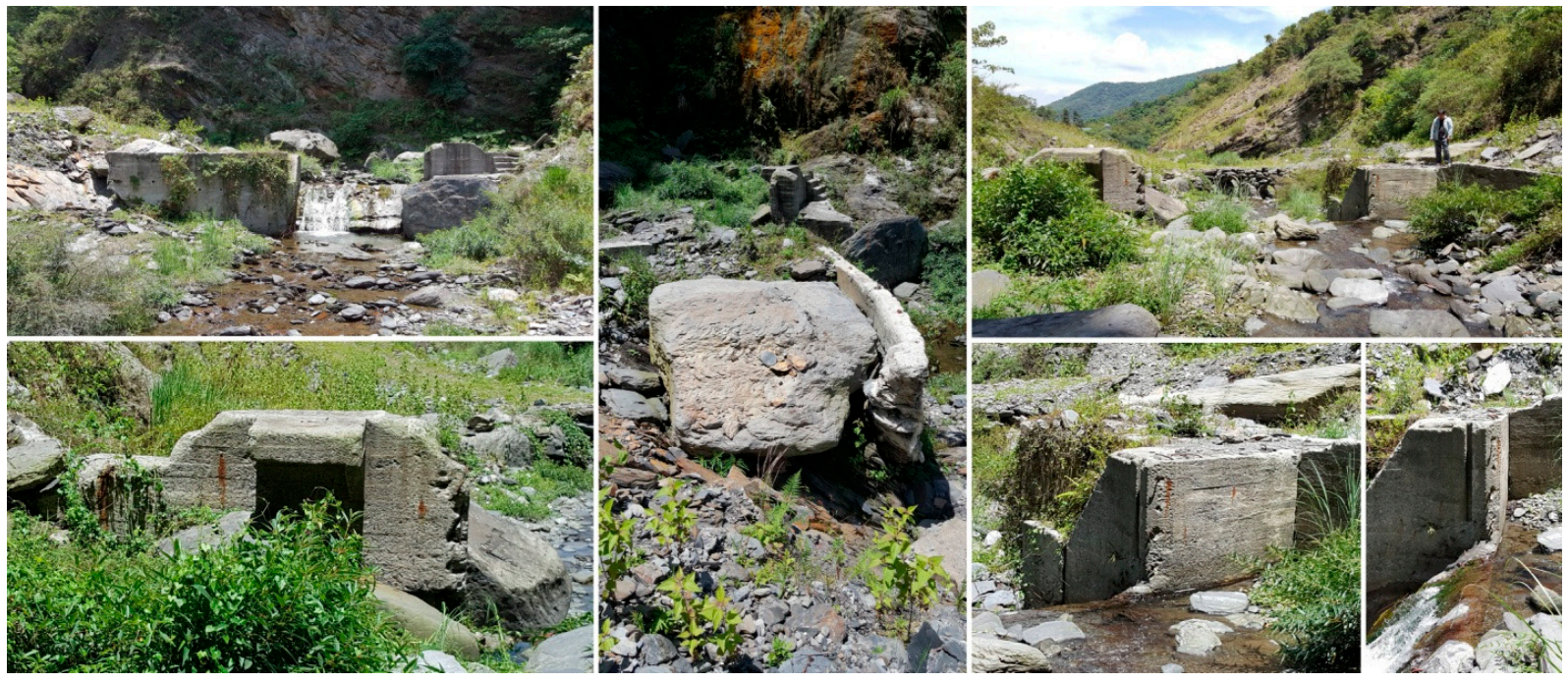

Fig. 5. Remains of the water intake weir show clearly shift of the dam body due to giant rocks from a landslide. (Source - Author)

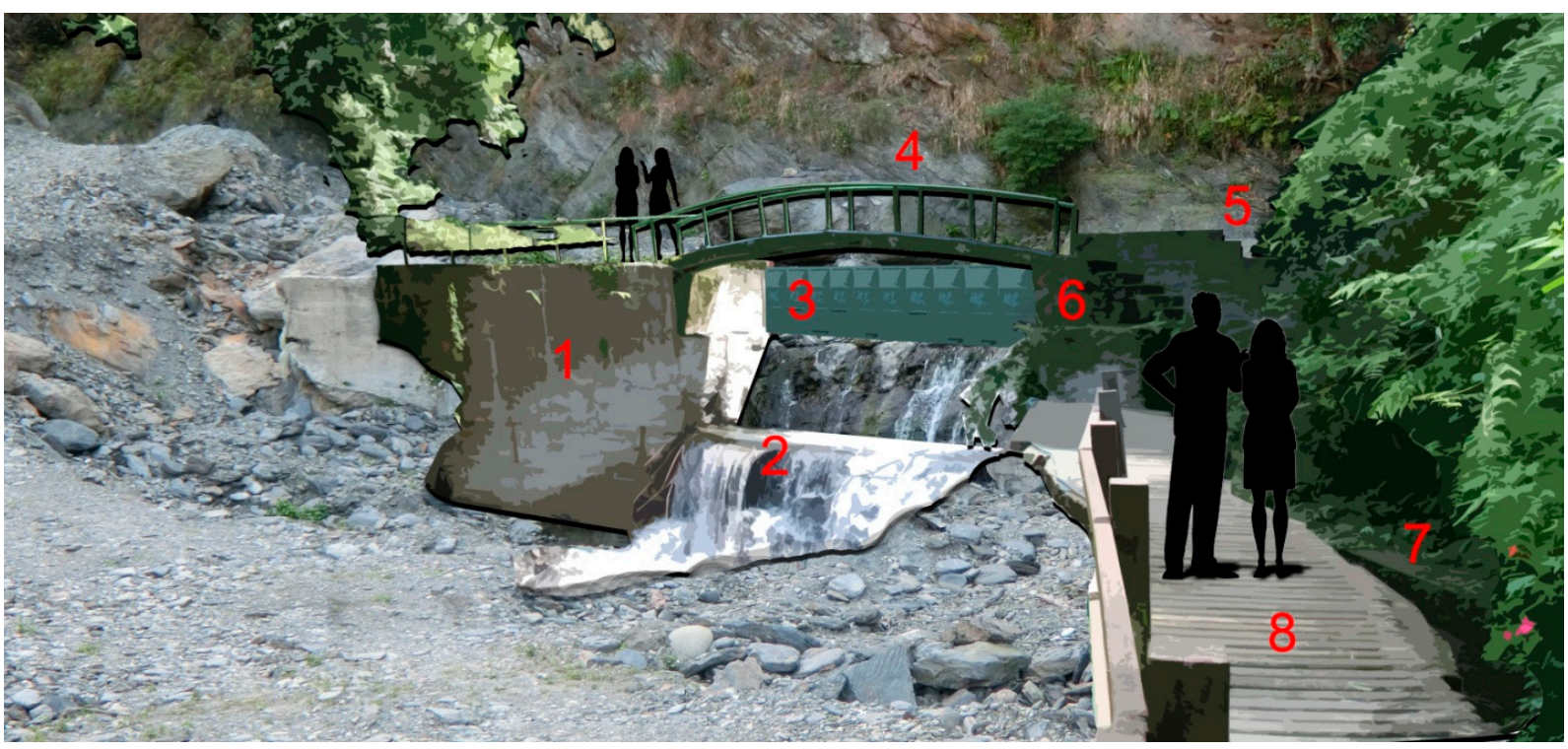

Fig. 6. Reconstruction of the diversion weir according to the old imagery. 1-the main body of the weir, 2-deflector, 3-original spillway gates, 4-Green bridge, 5-access stairs, 6-bridge stairs, 7supply channel, 8-old plank path. (Source - Author) 


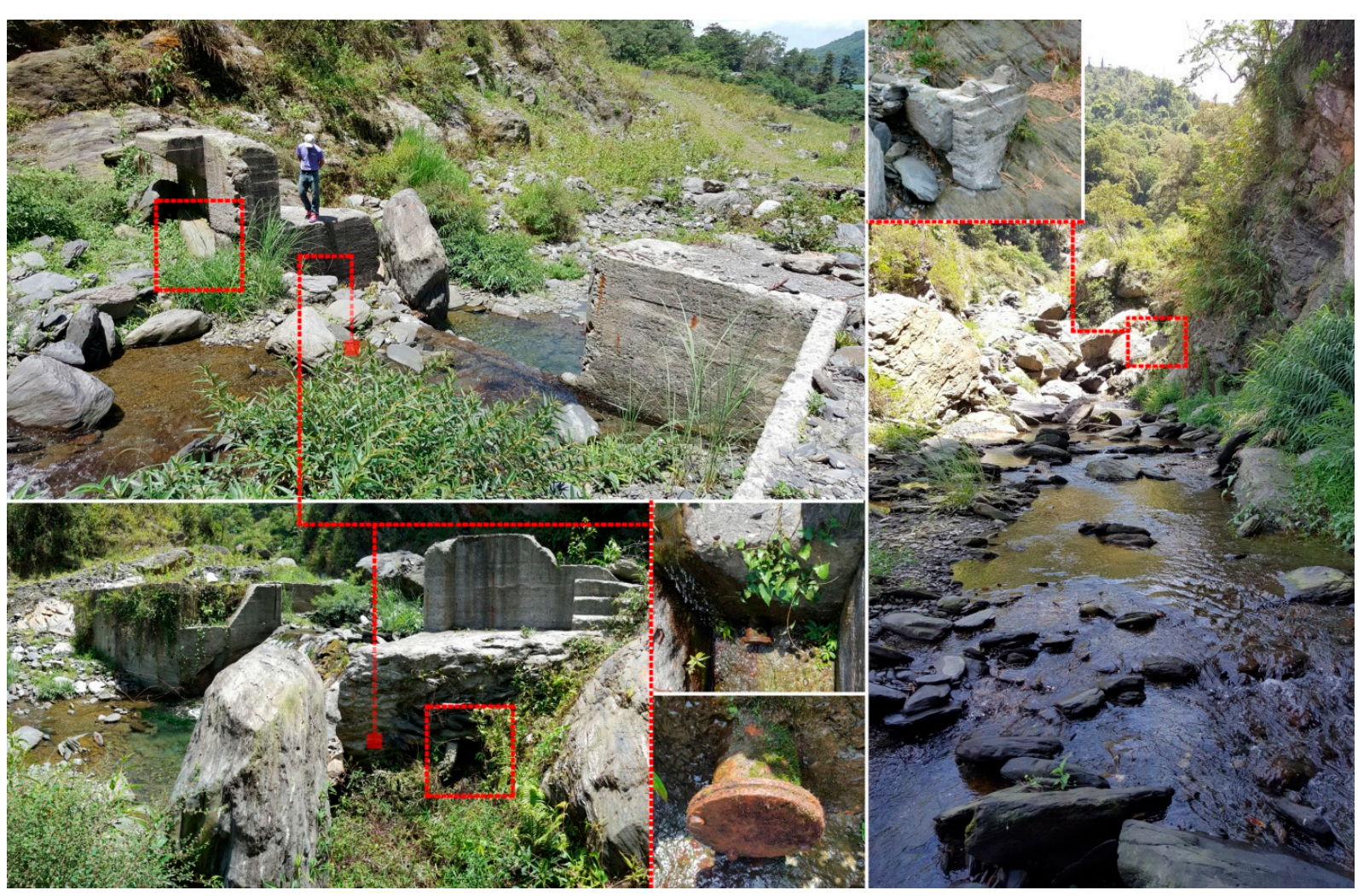

Fig. 7. Details of the intake weir showing the position of inflow and desilting openings on left. On right there is Shanping creek riverbed in front of the intake weir indicating the remains of the Lovers bridge. (Source - Author)
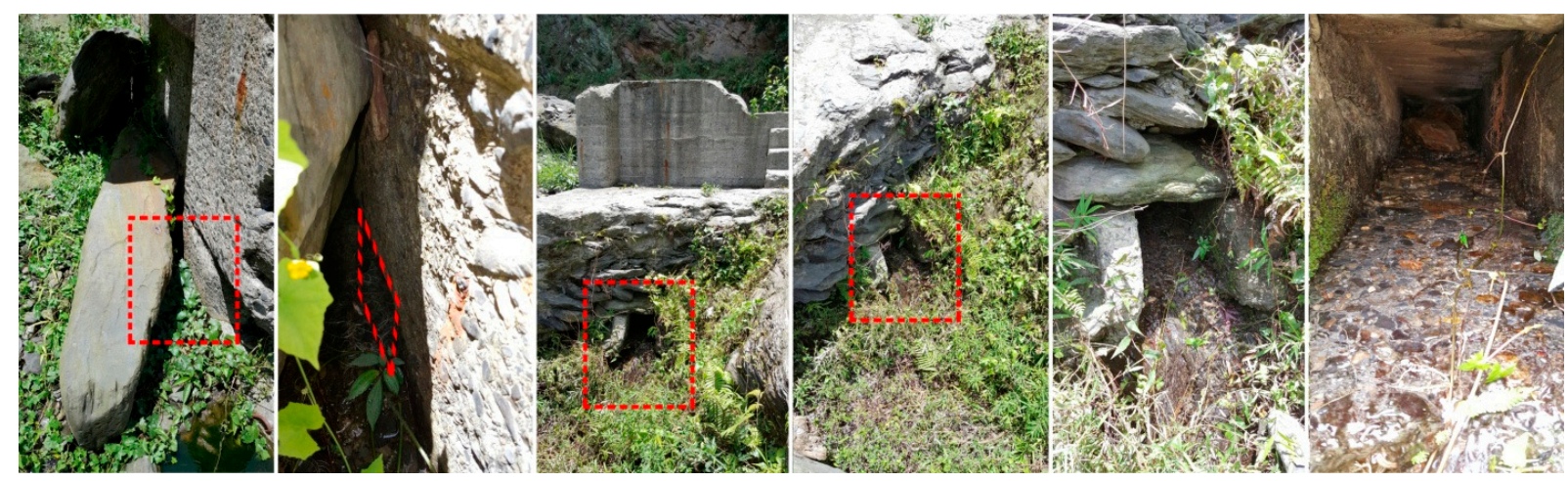

Fig. 8. Inflow opening is located behind a rock and is blocked with alluvial sand and rocks. On the other side of the dam the opening is clearly visible (Source - Author) 


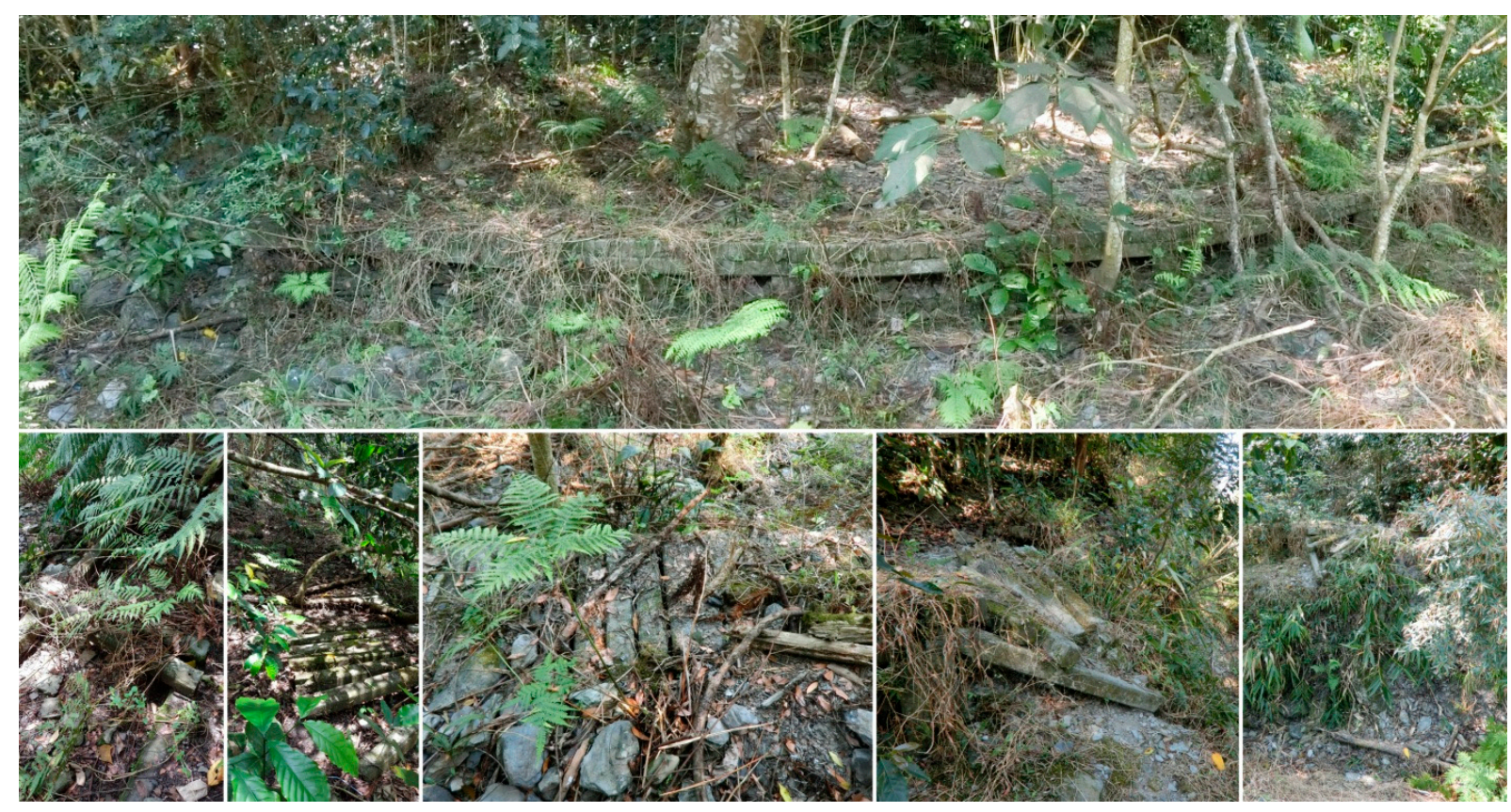

Fig. 9. Remains of the old plank path and supply water channel that was originally on the right side of the path (Source - Author)

\section{The headrace}

There are fragments of damaged old plank path with water supply channel still clearly tractable in the forest (Fig. 9). Based on the onsite measurements the overall path was $150 \mathrm{~cm}$ wide including the supply channel and its construction. The $120 \times 12 \times 12 \mathrm{~cm}$ planks were laid on $12 \times 12 \mathrm{~cm}$ concreter rails in $110 \mathrm{~cm}$ distance between axis supported by concrete pillars mainly on the side facing the Shanping creek. The supply channel followed the plank path on right side. It was embedded into the ground approximately on the same level as the edge of the path rails and had $U$ shape with inner dimensions $35 \times 35 \mathrm{~cm}$ and construction thickness around $12 \mathrm{~cm}$.

The remaining visible section is the final curve before the powerhouse where the channel originally departed from the path and continued toward the small channel diagonal enlargement about $70 \mathrm{~cm}$ wide and $200 \mathrm{~cm}$ long with screens which served as trash rack for keeping leaves and twigs from entering the turbine. After trash rack, the channel entered the small $200 \times 200 \times 50 \mathrm{~cm}$ forebay tank without overflow spillway, where water accumulates and if too much, water simply flowed over the ridge. From forebay, the water continued via enlarged flipped $\mathrm{T}$ shape aqueduct towards the water shaft with the turbine on the bottom. The beam of the aqueduct was $15 \mathrm{~cm}$ thick and approx. $95 \mathrm{~cm}$ width. The overall height of the aqueduct with base was $65 \mathrm{~cm}$ and the $U$ shape channel had most likely the same dimension as the supply channel to keep the water flow volume equal. As to the stress analysis, the aqueduct construction was supported in three points. It was laid on stepped face gravity wall mainly for slope stabilization which also worked as a grounding for forebay and single flat slab-column placed in the middle of the aqueduct and at the end, it laid on column bracket protruding from concrete water shaft at the powerhouse side. Despite the strong aqueduct axial and torsion stress resistance, the lateral security was performed only by middle column entasis which was also the cause of easier collapse during the flood event (Fig. 3,11,17). 


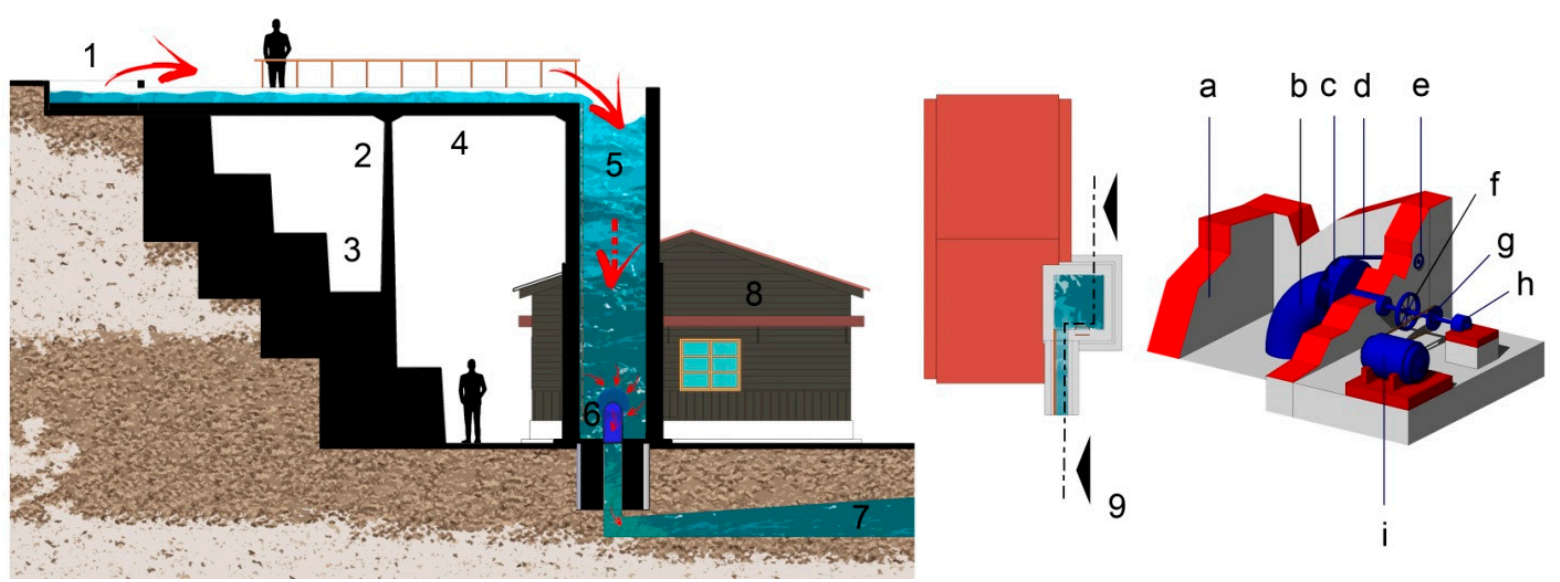

Fig. 10. Cross section of the hydraulic structure of Shanping hydropower plant and details of the turbine 1-forebay tank, 2-column supporting the aqueduct, 3-Slope reinforcement and base for the hydraulic structures, 4-Aqueduct, 5-Water shaft, 6-Openflume Francis turbine, 7-Power house draft tube, 8-Power house, 9-Crosssection plan, a-Water shaft walls, b-Turbine draft tube, $c$-guided vanes regulation, $d$-guided vanes regulation levers, $e$-throttle valve for steeples speed control, f-Flywheel, g-Transmission via belt, h-turbine axel bearing, i-Generator. (Source Author)

\section{The shaft and turbine}

The shaft (Fig. 10,11) is the eye-catching part once entering the former powerhouse site. It is laying nearby the old public toilettes both filled with alluvial sand and rocks. The shaft was clearly flushed on the side, away from the original area during the disaster. The shaft was made from steel reinforced concrete with further specifications. The shaft has a rectangular shape, approximately $800 \mathrm{~cm}$ of the total visible height with $20 \mathrm{~cm}$ wide and $40 \mathrm{~cm}$ deep footing. The overall height of the shaft can be clearly divided into two parts, the $450 \mathrm{~cm}$ tall top, and the $350 \mathrm{~cm}$ tall bottom.
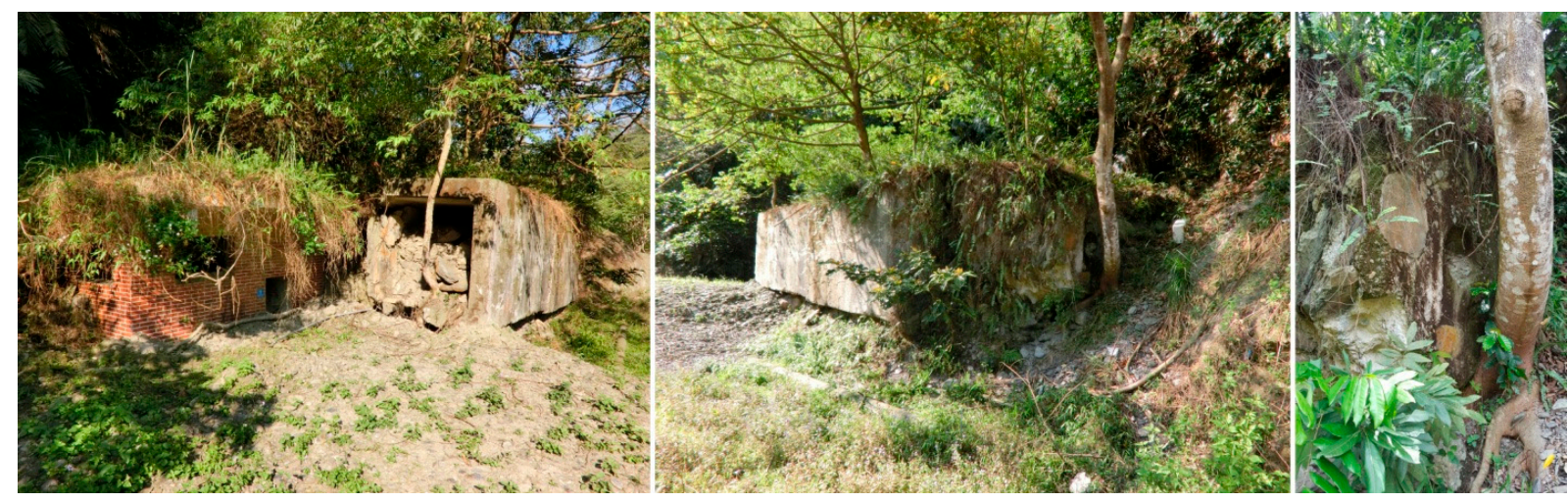

Fig. 11. The remains of the concrete shaft with outflow opening and turbine most likely buried inside. (Source - Author) 
The outside width of the shaft varies, ranging from $200 \mathrm{~cm}$ on the top part and changing to 212 on the bottom part due to necessary reinforcement for withstanding the water column pressure. The inside width is $140 \mathrm{~cm}$, walls are $30 \mathrm{~cm}$ thick on top and $36 \mathrm{~cm}$ on the bottom part. There are $13 \times 13 \mathrm{~cm}$ inside chamfers reinforcing the corners of the shaft. On the top of the shaft, there is exposed reinforcement consisting of no patterned reinforcing bars with width ranging from 1 up to $1,5 \mathrm{~cm}$. These were clearly sheared off during typhoon indicating the place of the aqueduct attachment. Accept the reinforcement, there are also steel tubes with $2 \mathrm{~cm}$ diameter exposed on the top of the shaft, these were most likely anchors for steel aqueduct and also ladder used for inspections of the turbine.

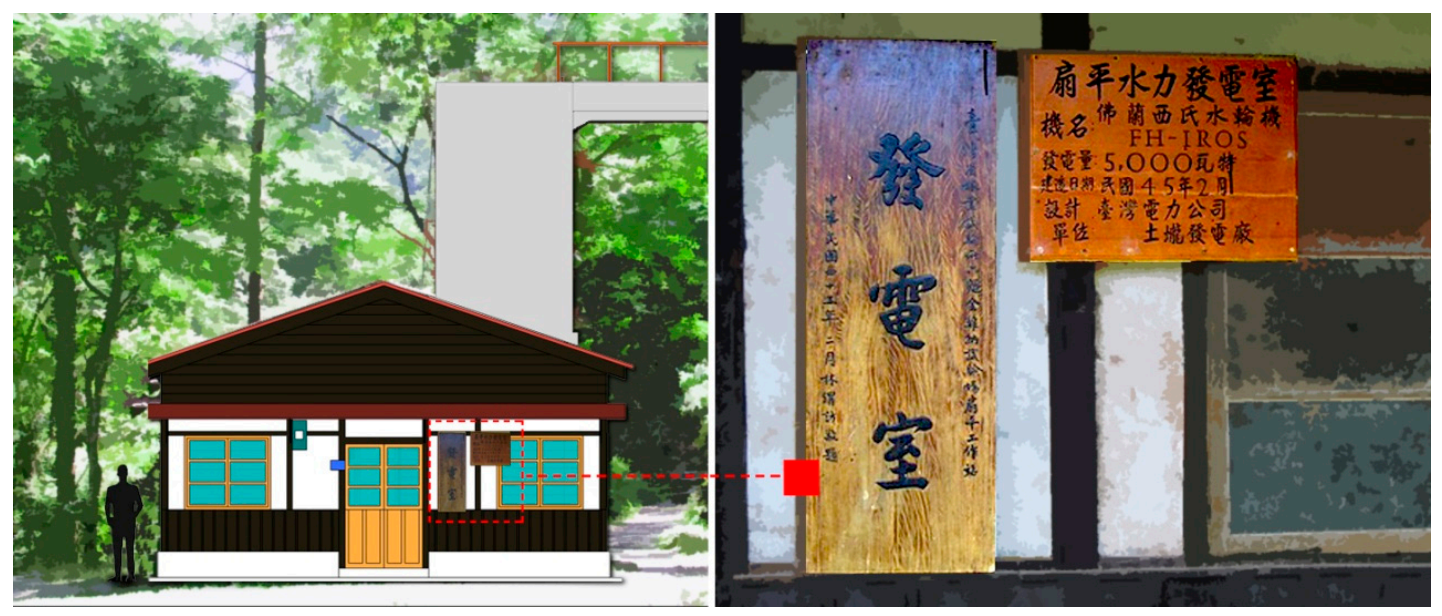

Fig. 12. The name and data plate originally mounted on the powerhouse revealing the name of the powerhouse, turbine type, installed capacity, builder-contractor, and date of commissioning. (Source - Taipower, Liugui Unit, and Author)

The grounding has tubular centric shape with depth around $150 \mathrm{~cm}$ and diameter $180 \mathrm{~cm}$. It is made from plain concrete and rocks found directly on site. In the middle of the grounding column, there is a circular opening with a $45 \mathrm{~cm}$ diameter indicating the end of the turbine draft tube. Under the shaft grounding, there was an inclined outflow due to the water pressure preservation leading to the tailrace tunnel ending up by 5 stage cascade made from concrete and rocks under the power house, returning water back to the Shanping creek
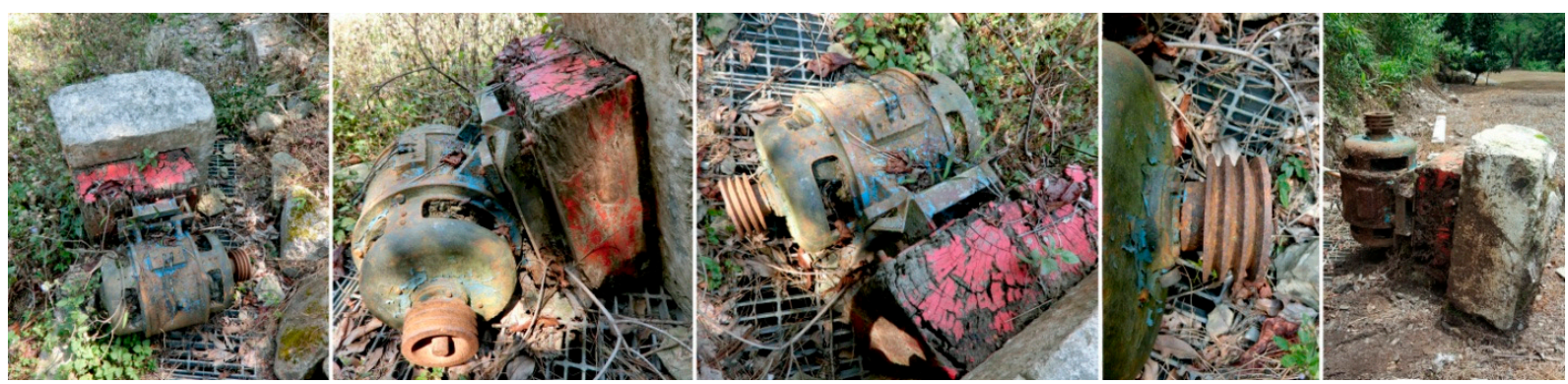

Fig. 13. Electric generator, the last picture shows that the data plate is already rusted. (Source Author) 
Unfortunately, the shaft leans the slope by the side where the turbine was attached to the powerhouse via axle so that there are no side opening visible. The turbine was an open flume horizontal axis Francis type (known in Germany as Shaft turbine) with marking FH-IROS [12](Fig. 10,12) attached to the wall of the shaft therefore it is most likely still buried inside the shaft, however it is not visible due to sand and rocks which filled the $2 / 3$ of the shaft volume and block even the draft tube opening.

Since Shanping power plant was designed after the Japanese occupation period, the plausible explanation would suggest that the turbine came from Europe. According to interview with the former power plant builders, it might be Netherland or also Germany where these kind of turbines with equal size are quite common and could be found in historical water mills even today[12].
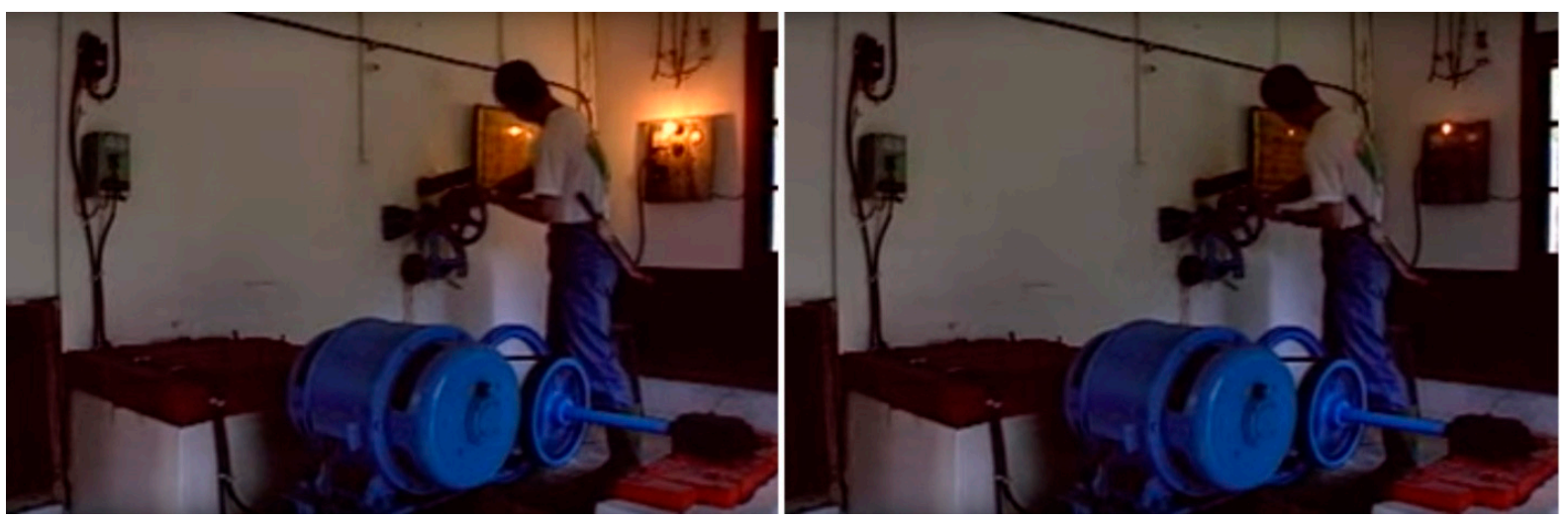

Fig. 14.[13] Interior of the Shanping hydropower plant including three phase self-excited generator powered by triple V-belt transmitting torque from turbine shaft with flywheel connected to the horizontal Francis turbine behind the wall.

The power plant operator is clearly synchronizing the frequency by turning the turbine throttle valve for steeples speed control looking at the luminosity of synchronizing lamps before he switches the transmission handle. He may do so when both lamps got the same luminosity, therefore, the frequency of the generator and frequency of the grid are the same. (SourceCourtesy of Council of Agriculture Executive Yuan)

\section{The generator}

The three-phase blue colored generator with green steel anchor construction mounted on wooden bed fixed on concrete base is located in the middle of the parking area (Fig. 13), where it was obviously brought during the aftermath reconstruction works. The generator data plate is already rusted, therefore any details were lost. However judging from the wooden information plate at the powerhouse from the old pictures, introduction video clip made by TFRI(Fig. 14) and individual interviews, the installed capacity was $5 \mathrm{~kW}$, it was placed horizontally on the left side from the turbine axle with flywheel to which it was connected via triple V-belt. The country of origin was suggested either Taiwan or the same as the turbine. 


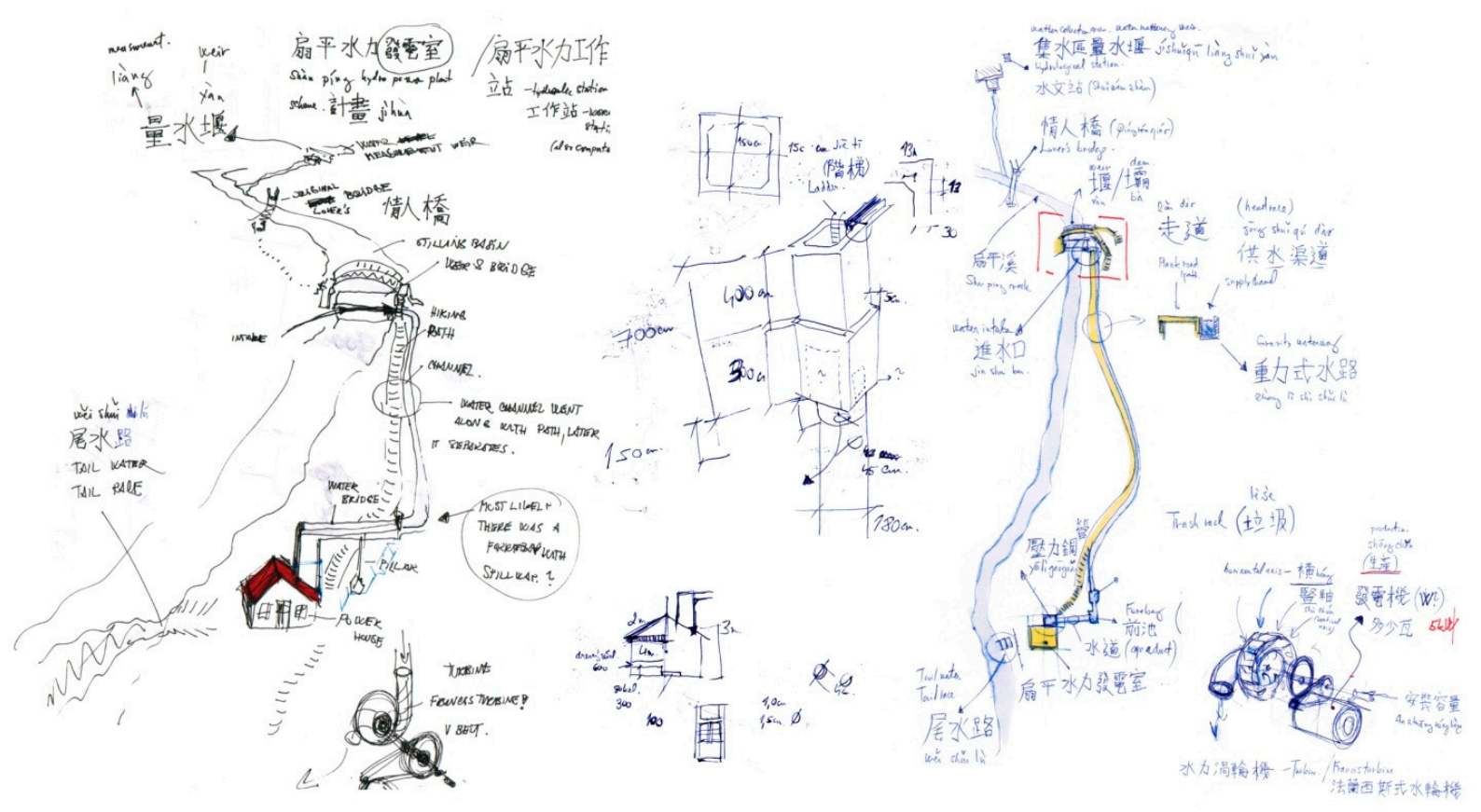

Fig. 15. Development of sketches of the Shanping micro hydropower plant. Left to right - an estimated situation after the first mapping on March 28th, 2017 and after the second mapping on June 6th, 2018. (Source - Author)

\section{Reconstruction}

The map of the overall Shanping riverbed area was made based on GIS maps from Academia Sinica (Fig. 4) The powerhouse reconstruction was carried away by CAD drawings, Sketch-up - 3D drawings and original site fitting(Fig. 16, 17).

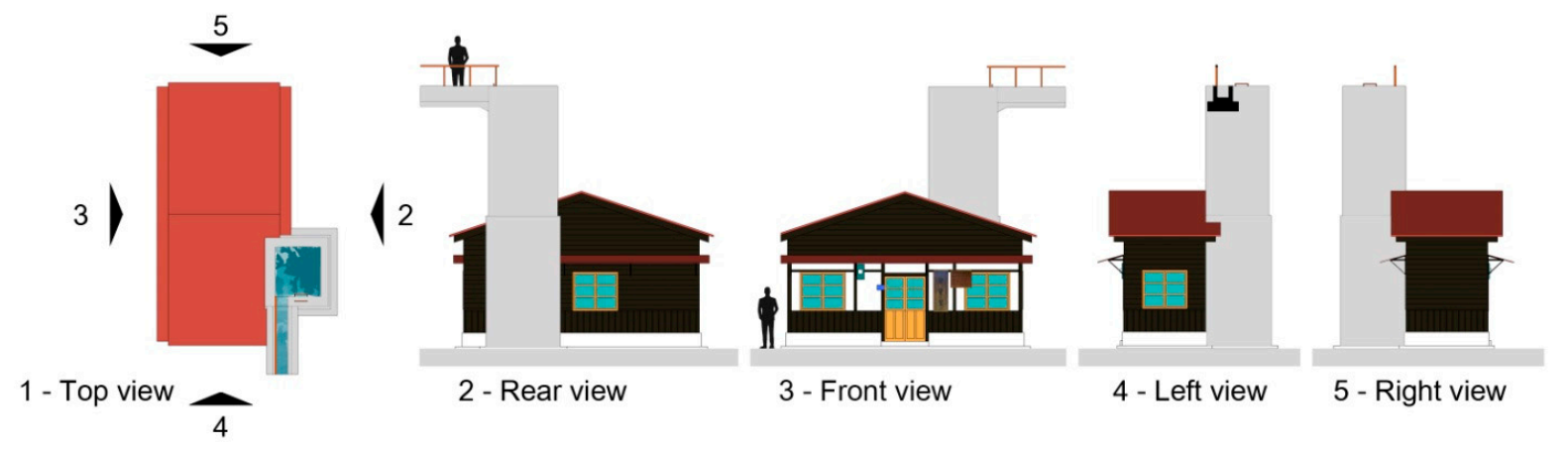

Fig. 16. 3D orthogonal vies of the Shanping hydropower house along with the concrete water shaft. (Source - Author) 

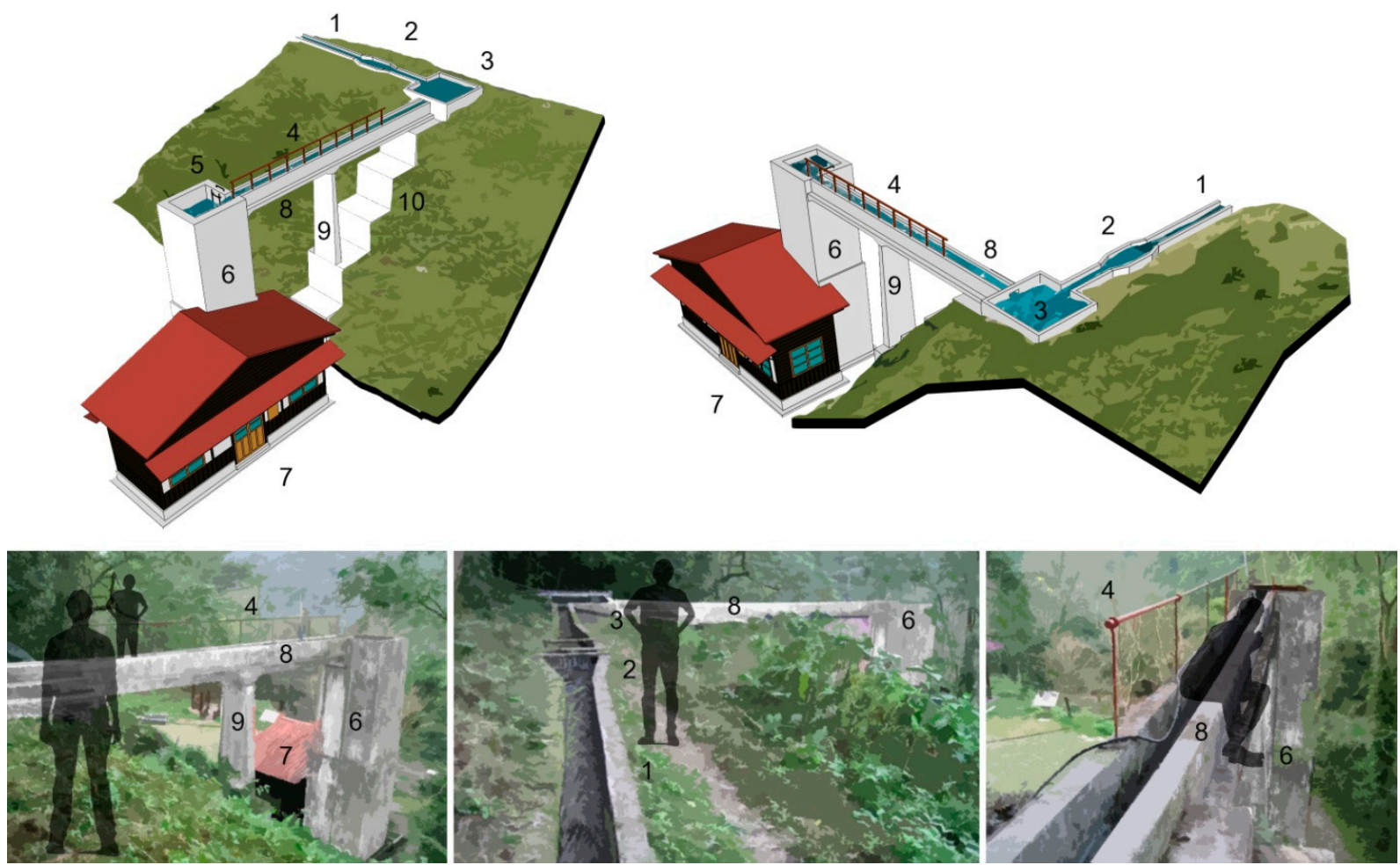

Fig. 17. Perspective views of the Shanping hydropower house with the entire hydraulic construction system.1-Water supply channel, 2-Trash rack, 3-Forebay tank, 4-Aqueduct rail, 5Concrete shaft ladder, 6-Concrete shaft, 7-Powerhouse, 8-Aqueduct, 9-Supporting column, 10Slope reinforcement and base for the hydraulic structures. (Source-Author)

\section{Potential}

The micro hydropower potential of the Shanping area is still high and more interesting than ever since the original function of the Shanping area has changed over time as well as the hydropower technology along with environmental impact research methods[14]. Even if the Shanping power plant would be rebuilt using original design, the regulating diversion weir or inflatable weir might cause a significant changes in the hydropower generation, also application of nowadays turbine technology in combination with wind, and solar energy might create a suitable conditions for micro PS hydropower plant which would be able to easily supply the whole area and even create some surplus energy that could be either stored, used for charging vehicles e.g. Gogoro scooter, Luxgen MPV types or heat the fish tank.

\section{Conclusion}

Shanping micro hydropower plant is one of the examples how sustainably were people thinking before. In Taiwan, the current research estimates that there were far more private and national hydropower plants before the unification of the national Taipower company. There are fragments of previously mentioned Neiwan power plant, Fanshekeng and via Taipower restored Ruanqiao, but also recently excavated, untouched Dongjin and ruins of Fengping-xi in Hualien, then there are Zhiben, Guanshan and Fujia-xi ruins in Taitung or hydropower plant adjacent to the Jingua-shi gold mine from Japanese occupation period. 
In fact even today there are several private pico and micro hydropower plants flourishing in the past decade. The significant number is located in southern Taiwan, Chiayi area along the Zengwen river and Wushantou reservoir, but there are pico hydropower plants in Yilan, Miaoli or Nantou. All these data only concludes the importance of the water element in the micro-urban structures and support the decentralized generation of the remote and micro urban areas as a step forward to sustainable growth in coherence with nature.

To conclude Taiwan is an island country surrounded by ocean, therefore, the advantage is that all the rivers start and end in the country so the water management is crucial not only for hydropower, but also for keeping the drinking and industrial water inland. And if the ocean's salinity is counted in the possibility to establish an osmotic power plant is undoubtedly there, helping to expand the overall Taiwan hydro-energy potential in use(HEP) which represents something above $21,6 \%$, which is in comparison to the surrounding countries and level of Taiwanese development plaintively low. By expanding the HEP in use also helps significantly in decreasing the 97,9\%(2013) import rate of consumables per year. Shanping power plant with extensive watersheds and rainforest was one of the good stand alone examples Taiwan could definitely learn from.

\section{Acknowledgement}

Special thanks goes to Dajia xi power plant namely Mr. Yan-Zhen Liu for communication assistance, Gaoping power plant - Liugui unit namely Mr. Qiang Zheng and Mr. An-Jing Huang, members of the Council of Agricultural Executive Yuan, Shanping Forest Ecological Scientific Garden and TFRI - Taiwan Forestry Research Institute namely Mr. WenChih Lin and Rong-San Zhu for additional information and assistance during the visits of the study site.

Foremost I would like to acknowledge the meeting with the former staff members of the Liugui unit and the original builders of the Shanping micro power plant Mr. Jin-Rong Lin and Jin-Fa Peng, who answered several key point questions regarding the operation of the power plant.

My ultimate thank goes to my fellow researcher and friend Mr. Deng Zhongwen, who allowed me to access his extensive research on historical files and with whom I share the passion for Taiwan hydro power plants research.

Research is component of the project named: "Mapping of the Taiwanese hydropower plants" supported by VEGA no.: 1/0202/15 - "Sustainable and Safe Water Management in Buildings of the 3rd Millennium", ERASMUS+ KA107, Post-doctor Visegrad-Taiwan Scholarship, University Science park TECHNICOM for application of innovations with support of knowledge technologies - Phase II“ and ITMS2014 - code 313011D232.

\section{References}

[1] DENG, Z. W. (2018) Talk about 100 years of Taitung Electric Industry development: 100 years of power development. Taitung City, Taiwan: Taitung District Office of Taiwan Power Company.

[2] LIN, B.L (2008, 1. 29.). Neiwan Power Station Site. 17.6.2018 from https://blog.xuite.net/ evanhoe/balihun/15526726

[3] LIN, B.Y (2008, 3. 12.). Jiangjian's Policy, Runchiao Hydropower Station. 17.6.2018 from https://pylin.kaishao.idv.tw/?p=455

[4] KO, T $(2014,7$. 26.). Fanshekeng hydropower house. 17.6.2018 from https://kotaine.blogspot.com /2014/07/blog-post_26.html 
[5] Taiwan Forestry Research Institute. (12/2013). Photo Gallery of the Liouguei Forestry. Taipei, Taiwan: Council of Agriculture Executive Yuan.

[6] Sunwards Technologies Co., Ltd. (2018). Shan-Ping Forest Ecological Garden. 5.7.2018, from http://okgo.tw/butyview.html?id=2274

[7] Zhou-Fusan, Zhu-Rongsan, Lin-Wenzhi, Chen-Yongxiu and Cai-Jifeng. (12/2012). Shanping Forest Ecological Science Park Introduction Manual. Taipei, Taiwan: Taiwan Forestry Research Institute.

[8] Academia Sinica. (2018). Taiwan's century-old history maps. 25.6.2018, from http://gissrv4.sinica. edu.tw/gis/t whgis.aspx

[9] Tkáč S̆. (5/2018). Hydro power plants, an overview of the current types and technology. Selected Scientific Papers - Journal of Civil Engineering. Volume 13 (issue s1),115-126. DOI: https://doi.org/10.1515/sspjce-2018-0011.

[10] Wang-Peirong. (12/1995). Fanping Nature Education Area, Trail Description Manual. Taipei Taiwan: Taiwan Forestry Research Institute.

[11] Lu-Xiangyu, Huang-Liangxin \& Xie-Hanqin. (2010). Why did Morakot typhoon hit the Fanping Park.. Forestry Research News. Volume17 (issue 1), 45-48. https://www.tfri.gov.tw/main/downloa d.aspx?dlfn=93\%E8\%99\%9F_\%E6\%9 E\%97\%E6\%A5\%AD\%E8\%AB\%96\%E5\%A3\%87_1.pdf.

[12] CIT-Solutions e.U.. (2018). Ehlinger Mühle-Alle Bilder zur Turbinenrevision. 15.6.2018, from http://www.ehlinger-muehle.at/?fancy-gallery=alle-bilder-zur-turbinenrevision

[13] Council of Agriculture Executive Yuan. (10.7.2013). Forest Cinema Fanping Nature Education Zone. 20.6.2018, from https://www.youtube.com/watch? $\mathrm{v}=\mathrm{rFaVu} 8 \mathrm{nGyTc} \& \mathrm{t}=2 \mathrm{~s}$

[14] ZELEŇÁKOVÁ, M., ZVIJÁKOVÁ, L. \& PURCZ, P. (2013). Small Hydropower Plant Environmental Impact Assessment - Case Study. International Journal of Emerging Technology and Advanced Engineering. Volume 3 (issue 4),35-42. http://www.ijetae.com/files/Conference_IC MTSET_2013/IJETAE_ICMTSET_06.pdf. 